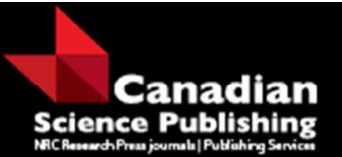

Canadian Journal of Forest Research

Revue canadienne de recherche forestière

\title{
Comparison of sampling methods for estimation of nearest- neighbor index values
}

\begin{tabular}{|r|l|}
\hline Journal: & Canadian Journal of Forest Research \\
\hline Manuscript ID & cjfr-2016-0239.R3 \\
\hline Manuscript Type: & Article \\
\hline Date Submitted by the Author: & 01 -Dec-2016 \\
\hline Complete List of Authors: & $\begin{array}{l}\text { Mauro Gutiérrez, Francisco; Oregon State University, College of Forestry. } \\
\text { Forest Engineering, Resources and Management. } \\
\text { Haxtema, Zane; Oregon State University } \\
\text { Temesgen, Hailemariam; Oregon State University }\end{array}$ \\
\hline Keyword: & $\begin{array}{l}\text { species mingling, diameter differentiation, head water stream, density } \\
\text { management studies, riparian zones }\end{array}$ \\
\hline
\end{tabular}

\section{SCHOLARONE ${ }^{m}$ \\ Manuscripts}


Abstract

Neighborhood-based indices such as mingling index and diameter differentiation are a set of 9 diversity measures that are based on the relationship between a reference tree and a certain number of 10 nearest neighbors (i.e. trees to which it has the lowest horizontal distance). Using stem-mapped data 11 from eight headwater sites, we compared the relative bias and relative root mean square error (relative 12 to the true mean of each site) of several different methods of choosing reference trees for calculation of 13 diameter differentiation $(\bar{D})$ and species mingling $(\bar{M})$ index. Indexes were defined using 2, 3 and 4 14 neighbors and methods for selection of reference tree were: random selection of a tree in a fixed radius 15 plot $(F I)$, random selection of a tree in a variable radius plot $(V A)$, azimuth selection method $(A Z)$ and 16 nearest tree selection $(N T)$. In general, the relative bias was lower than $\pm 2.5 \%$ for $\bar{D}$ and lower than

$17 \pm 10 \%$ for $\bar{M}$ regardless of the method. The $F I$ method consistently had the lowest relative bias and 18 relative root mean squared error. The $N T$ and $A Z$ methods were second in terms of relative root mean 19 squared error for $\bar{D}$ and $\bar{M}$ respectively. Simplicity of these two methods might outweigh their slightly 20 worse performance. 


\section{$1 \quad 1$ Introduction}

According to Gadow et al. (2012) the term forest structure "usually refers to the way in which

3 the attributes of trees are distributed within a forest ecosystem". Tree growth and mortality shape the

4 forest structure and can be influenced by multiple factors, ranging from human intervention to biotic

5 and abiotic events and processes. But the forest structure itself, modifies the driving factors of tree

6 growth, mortality and regeneration (Gadow et al. 2012). Silvicultural interventions (Franklin and Spies

7 1991) modify forest structure pursuing an enhancement in productivity and/or the ecological functions

8 of the forest at hand. A proper quantification of forest structure is therefore necessary for a better

9 understanding of forest history and dynamics and for guiding the forest management.

Different forest structures are better suited for different management objectives (i.e.

11 production, recreation or conservation of ecological values). To obtain those forest structures that best

12 suit specific objectives, management systems try to mimic the disturbance regimes that generate the

13 desired structures. Certain forest management systems and their associated structures are therefore

14 preferred to others depending on the management goals. On one end of the gradient of forest management systems, even-aged forestry using clear cuts, shade-intolerant species and short rotation

16 periods, is usually the selected method for production objectives. This management system tries to 17 imitate high intensity disturbances such as forest fires and has certain advantages for harvest 18 operations, however, it does not completely imitate the disturbance regime it is meant to mimic (García19 Abril et al. 2013 p. 289). For example, trees and snags remaining after a fire produce conditions that 20 facilitate or accelerate the regeneration, and a complete tree removal fail at producing such conditions. 21 In addition this system produce over-simplified forest structures with a highly homogeneous 
22 composition, similar to those obtained in the first stages of the ecological succession. Such simplification

23 in structure results in a larger susceptibility to biotic and abiotic damages and in a lower resilience.

Management systems known as "close-to-nature" silviculture or continuous cover forestry (CCF), advocate a closer adaptation to natural processes and lead to more complex uneven-aged forest structures, similar to those found in mature forests (Schütz et al. 2012). This type of management

27 appeared in the ninetieth century as a response to the problems associated with intense even-aged management and had a revival in the last decades of the twentieth century. Uneven-aged management

29 systems are better suited for scenarios where multiple objectives have to be considered. They result in lager diversity (structural and biological), are better suited for production of high quality wood and are

31 able to outperform even-aged management systems in terms of economic balance (Howard and 32 Temesgen 1997, Schütz 1997). A thorough review on the history of CCF and comparisons between evenaged and uneven-aged management systems can be found in García-Abril et al. (2013 pp. 289-319). or to a single scale. Forest structure is a multidimensional and multiscale property. Different descriptors have been proposed to characterize its different facets at different scales. We will restrict the scope of

37 this manuscript to quantifying forest structure at stand level which is usually linked to the concept of $\alpha$ diversity (i.e., fine scale diversity) proposed by Whittaker (1960).

To quantify stand level structure, standard aggregated measures of structure such as stand density, basal area or volume can provide the necessary information to characterize stands for even-aged forest management. However, they do not suffice to fully characterize forest structure (Pretzsch 1997) and

42 contain no information on the spatial arrangement of live trees within a stand (Pommerening 2002), 
44 more sophisticated presentations such as a stand table, can tell us "what is out there" but not "how 45 what is out there is arranged". Zenner and Hibbs (2000) present a hypothetical example where two 46 different stands have identical tree densities, basal areas and diameter distributions, and yet have very 47 different forest structures as a result of differing management regimes. Spatial functions, such as 48 Ripley's K (Ripley 1977) or the pair correlation function (Pommerening 2002), describe the spatial 49 pattern of trees across a continuous range of inter-tree distances. However, they require knowledge of 50 the coordinate positions of all trees within a plot, limiting their use in practical forest inventory 51 applications. Furthermore, they can be difficult to explain to forest managers who may lack advanced 52 statistical training.

In response to the need for a set of analytical tools to quantify forest structure at stand level, 54 nearest-neighbor indices (NNI) have received much attention from the forest research community in 55 recent years. By focusing on the relationship between a given tree (the "reference" tree) and a fixed 56 number of its nearest neighbors (generally three or four trees), NNI are capable of quantifying structural 57 complexity at a very fine scale (e.g. Haxtema et al. 2012). Designed as a framework for characterizing 58 structure without the need for expensive stem mapping (Gadow and Pogoda 2000), NNI have been 59 promoted for their potential use in operational inventory programs (Pommerening 2006) and have been 60 widely used in descriptive studies to quantify the structure of stem-mapped plots (e.g. Aguirre et al. 61 2003, Saunders and Wagner 2008, Mason et al. 2007, Haxtema et al. 2012). Neighborhood-based indices 62 can be seen as fine-scale measurements of structural diversity, while conventional indices such as stand 63 table measure diversity at the stand level, and other diversity measures such as Shannon and Simpson's 64 indices require proportional data (i.e., number of individuals of each species and total number of 65 individuals). 
Tree-size variability, species composition and spatial distribution of trees have been typically

67 considered as the main features that describe forest structure at stand level (Pommerening 2002, Aguirre et al. 2003) and different NNI have been proposed to measure those features. A comprehensive review of available indexes, not restricted to $\mathrm{NNI}$, to analyze forest structure can be found in (Pommerening 2002). The two commonly used NNI indices are differentiation index $D_{t}$ developed by

71 Gadow (1993) and species mingling $\left(M_{t}\right)$ developed by Füldner (1995). Below we will briefly describe

72 these indices and their uses.

The differentiation index $\left(D_{t}\right)$ describes the degree of interspersion of trees of different sizes. While

74 this index can describe the differentiation of any size-related variable (e.g. diameter at breast height 75 (DBH), height, or volume), only diameter differentiation (the differentiation of $\mathrm{DBH}$ ) will be considered 76 here. Higher values imply higher differentiation (i.e. more fine-scale variability in size); lower values 77 imply lower differentiation. For the $i^{\text {th }}$ th reference tree and its $j^{\text {th }}$ nearest neighbor, diameter 78 differentiation $\left(D_{t}\right)$ is estimated as:

$$
D_{t}=\frac{1}{n} \sum_{j=1}^{n}\left[1-\frac{\min \left(d b h_{i}, d b h_{j}\right)}{\max \left(d b h_{i}, d b h_{j}\right)}\right]
$$

79 where $\min \left(d b h_{i}, d b h_{j}\right)$ is the smaller DBH of the two trees, and $\boldsymbol{\operatorname { m a x }}\left(d b h_{i}, d b h_{j}\right)$ is the 80 larger.

81 The $D_{t}$ index can be interpreted as follows (Pommerening 2002):

1) $D_{t}$ index values from $0.0-0.3$ are evidence of small differentiation. The tree with the smaller DBH is $70 \%$ or more of the neighboring tree's DBH. 


$$
M_{t}=\frac{1}{n} \sum_{j=1}^{n} v_{j}
$$

94 where $n$ is the number of neighbors considered and $v_{j}$ is 0 if the $j^{\text {th }}$ neighbor is of the same 95 species as the reference tree, and 1 otherwise.

97 unit of information for forest structure characterization (Pommerening 2002). However, for comparative 98 studies analyzing different edge-bias-corrections methods, the arithmetic mean of all individual NNI 99 values has been considered as the parameter of interest, and the performance of different methods has been evaluated using their accuracy in estimating NNI population means (Pommerening and Stoyan

101 2006). We aim at providing references about the best method to select reference trees for NNI 102 calculation by considering a broad range of alternative sampling protocols, sites, and measuring option. 
103 At the expense of loosing interpretability in ecological terms, we will restrict our analysis to the 104 estimation of mean NNI values because analyzing the effect of multiple factors in distributions of NNI 105 would make results intractable.

Sampling all trees in relatively large plots of fixed radius is a common alternative in forest 107 inventories, however, this system will be sub-optimal in terms of efficiency (precision) for NNI 108 estimation. When relatively large plots (e.g. permanent plots) are installed, some similarity between 109 trees within a plot can be expected. Because of similarities between tree attributes within permanent 110 plots, difficulties to cover the range of different structural variations that might appear in one stand can 111 be expected. Thus, large plots will show some statistical inefficiency to characterize forest structure. In 112 many cases, temporary sample points are used if the cost of sample point establishment is small relative 113 to the cost of travel. Neighborhood-based indices were specifically designed to be easy to measure in 114 the field, so it may be more statistically efficient to distribute temporary sampling points and reference 115 trees throughout a stand rather than selecting them in permanent plots. Even though this alternative 116 seems to be the best for NNI estimation, minimal guidance exists for practitioners seeking to integrate 117 these indices into sampling protocols, and little is known about the best method of selecting reference 118 trees when commonly used systematic designs, where sampling points are located on the nodes of a 119 regular grid, are used. Instead of substituting standard measures of structure like basal area, volume or 120 dominant height, NNI are meant to complement those measures. Similarly, it is important to note that 121 the sampling for NNI is not supposed to substitute standard sampling procedures. It aims at providing 122 specific information about NNI indexes in a fast and reliable way. Aiming at providing references for 123 future inventories where $\mathrm{NNI}$ are measured we consider four different methods for selection of 124 reference trees. 
125 Two alternative methods based on plots can be employed to select reference trees. These methods 126 use either fixed radius $(F I)$ or variable radius $(V A)$ plots to select a relatively small group of candidate 127 trees. Selected trees are listed and then, a number of candidates, ranging from one the total number of 128 trees selected in the plot, are randomly drawn and considered as reference trees.

Gadow and Pogoda (2000) suggested that reference trees be selected with what we refer to as the "nearest-tree" (NT) selection method, whereby the nearest tree to a given sample point is selected as 131 the reference tree. Under this method, trees are selected with probability proportional to the area in 132 which they are the nearest tree. Thus, selection probabilities will be unequal in all but the most 133 uniformly-spaced populations. While lles (2009) describes an unbiased method for estimating inclusion 134 areas from field measurements, the added effort required to unbiasedly implement this method may 135 tempt the sampler to avoid it due to the high effort required for its implementation. Nonetheless, if the 136 bias incurred by treating a nearest-tree sample as an equal-probability sample is demonstrated to be 137 small in a given forest type, the nearest-tree selection method may be acceptable.

A method sometimes used in forest inventory is to subsample from a fixed plot by selecting the 139 first tree whose center is encountered in a clockwise sweep from north. This has been termed the 140 "azimuth" method ( $A Z$ ) by lles (1979 p. 23). As with the nearest-tree selection method, inclusion areas 141 will not be equal in most cases, and a satisfactory method has not yet been devised for measuring or 142 estimating inclusion areas in the field. However, it may be reasonable to ignore the bias incurred from 143 this sampling method if it is demonstrated to be small.

\section{Objective}



methods of reference tree selection for estimation of different $\mathrm{NNI}$ in headwater riparian forests of western Oregon. We selected diameter differentiation index (Pommerening 2002 after Füldner, 1995) and species mingling index (Aguirre et al. 2003 after Gadow, 1993) as descriptors of tree size and species composition variability.

\section{Materials and methods}

\section{$151 \quad 3.1$ Description of the stem maps}

Selected sampling methods were evaluated using data from eight sites located in stem-mapped research plots installed as part of the United States Bureau of Land Management Density Management

154 Study. Methods used to collect data are described in detail by Marquardt et al. (2010) and Eskelson et 155 al. (2011), and briefly summarized here. Plots were located in the Coast Range and foothills of the Cascade Range of western Oregon. Each 0.518 ha plot $(72 \mathrm{~m} \times 72 \mathrm{~m}$ ) was located such that a headwater 157 stream flowed through the approximate centerline of the plot. The coordinate position, diameter at breast height $(\mathrm{DBH})$, and species of all trees greater than $6.9 \mathrm{~m}$ tall or $7.6 \mathrm{~cm}$ in DBH were recorded.

All stem maps were composed of second-growth forest. Species composition was coniferdominated, with either Douglas-fir (Pseudotsuga menziesii (Mirb.) Franco) or western hemlock (Tsuga cedar (Thuja plicata Donn) was present on six stem maps and some stem maps contained yew (Taxus brevifolia Nutt.) or grand fir (Abies grandis (Douglas ex D. Don) Lindl.). The hardwood species red alder

164 (Alnus rubra Bong.), bigleaf maple (Acer macrophyllum Pursh) and black cottonwood (Populus balsamifera L. ssp. trichocarpa (Torr. \& A. Gray ex Hook.) Brayshaw) were a minor component of some 
166 stem maps (Marquardt et al. 2012). Species composition and average values for the species mingling 167 and diameter differentiation indexes computed with 2, 3 and 4 neighbors in each site are provided in 168 Table1.

\subsection{Parameter of interest}

The parameters of interest were the average values of the diameter differentiation $(\bar{D})$ and species

171 mingling index $(\bar{M})$ (Table1) for each stem map. Because trees near a plot edge may have immediate 172 neighbors that are outside the plot, bias can result from the calculation of index values when only trees 173 inside the plot are considered (Pommerening 2006). Considering Pommerening and Stoyan (2006) edge 174 effect were accounted for by using a toroidal edge correction (Ripley 1979) on each site.

Both, the diameter differentiation index and the species mingling index depend on the number of neighbors $\left(n_{n}\right)$ considered to compute each index. We considered three different number of neighbors

$177 n_{n}=2,3$ and 4 , as these are sensible values to use in operational forestry applications. If $n_{n}$ changes, the 178 index $y_{t}$, associated to each tree $(t)$ and the site averages $(\bar{Y})$ change too. To assess the importance of 179 the change in $\bar{Y}$, we tested by means of ANOVA analysis whether or not increasing the number of 180 neighbors from 2 to 4 resulted in different values for the average values of both indexes. We accounted 181 for the effect of multiple comparisons, and performed a Bonferroni correction (Dunn 1961) by dividing 182 the significance level $\alpha=0.05$ by the number of comparisons performed.

\section{$183 \quad 3.3$ Reference tree selection methods}


186

187

unbiased estimator of the population mean for general sample designs of fixed size $n$ (Horvitz and

Thompson 1952) is given by $\hat{\bar{Y}}_{H T}=\frac{\sum_{t=1}^{n} w_{t} y_{t}}{N}$, where sub index HT stands for Horvitz and Thompson, and $w_{t}$ is the reciprocal of the probability of selecting tree $t$. For equal probability sample designs this estimator becomes the sample mean. To make the methods comparable, and to take into account the particular characteristics of each selection method, several factors were considered and, when possible, approximated sampling weights were obtained for each tree.

First, to make the methods comparable, it was necessary to keep the number of measurements equal between selection methods. Since the $N T$ and $A Z$ methods only select one tree per plot, only one tree was selected from the FIand VA plots methods. Then, the selection protocol resulting for each of these methods can be described as follows. For the FIand method, a tree was sub-sampled from a fixed plot by drawing a random number from 1 to $F$ where $F$ is the number of trees in fixed the plot. When using the $V A$ method to capture trees, a tree was sub-sampled by randomly selecting one of $V$ trees captured in the variable radius plot with probability proportional to its basal area. Weights were then

$w_{t, F I}=F$ and $w_{t, V A}=V_{t} \frac{B A F}{B A_{t}}$, where the term $B A F$ is the basal area factor used in the variable plot and $B A_{t}$ was the basal area of the selected tree. It is important to note that both weights are approximations to the real weight of the trees for the described sampling protocols. For the $N T$ and $A Z$ methods it was impossible to obtain approximated weights for the selected reference trees and they were all equally weighted with a weight of 1 in subsequent estimations.

\subsection{Simulation of alternatives methods for reference tree selection}

A simulation algorithm was written in $R$ ( $R$ Core Team 2016) to simulate the field measurement performed using each of the described methods. Four sampling points were simulated at each of 500 
207 repetitions in each site. Since systematic sampling is far more common than random sampling in most 208 forestry sampling applications, this method of sample point placement was simulated. The first point 209 was randomly located within the lower-left quadrant of the stem map using the pseudo-random number 210 generator function in R. Subsequent points were placed on a $36 \mathrm{~m} \times 36 \mathrm{~m}$ grid so every quadrant of the 211 stand map had a plot included. The fixed plot radius and variable plot BAF were scaled to capture an 212 average of 3, 6 and 9 trees $\left(n_{t}\right)$. Finally, the four methods for selection of reference trees were applied 213 in each sampling point. This process was iterated 500 times, as we empirically observed that rate of 214 change for the accuracy statistics described in next section was negligible after 500 replications. sample point, it is necessary to factor the number of trees per sample point into the weighted sample 217 estimate produced by each selection process (lles 2003 p. 562). For each sampling method, each neighborhood-based index was estimated at iteration $k$ as a weighted average [3] of the sampled values in an attempt to obtain estimators resembling the Horvitz and Thompson (1952) estimator.

$$
\hat{\bar{Y}}_{k, j, m, n_{t}, n_{n}}=\frac{\sum_{t_{=1}}^{4} w_{t, k, j, m, n_{t}} y_{t, k, j, n_{n}}}{\sum_{t=1}^{4} w_{t, k, j, m, n_{t}}}
$$

Note that for each method $(m)$ and site $(j), \hat{\bar{Y}}_{k, j, m, n_{t}, n_{n}}$ always depends on $n_{n}$, and the iteration $k$.

221 For the FI and VA methods, the selected reference trees depend on $n_{t}$ but not for the NT and $222 A Z$ methods. For generality sub index $n_{t}$ was left on $\hat{\bar{Y}}_{k, j, m, n_{t}, n_{n}}$. Four reference trees are selected for 223 each site, iteration, $n_{t}$ and method. Trees are indicated with sub index $t$. The approximated weight for 224 the selected $t^{t h}$ tree selected at iteration $k$ in site $j$ by the $m^{\text {th }}$ method tree depend on $n_{t}$ which results 225 on reference tree weights indexed as $w_{t, k, j, m, n_{t}}$. Weights $w_{t, k, j, m, n_{t}}$ were assigned as explained in 3.3. 
226 Finally, the index value for the $t^{t h}$ tree selected at iteration $k$ in site $j$ by the $m^{\text {th }}$ method depend on

$227 n_{n}$. Therefore, reference tree values for the neighborhood-based indexes are indicated as $y_{t, k, j, n_{n}}$.

228 The sampling methods were evaluated for estimation of species-specific index values for Douglas-

229 fir (DF), western hemlock (WH), western red cedar (RC) and, red alder (RA); the four species that

230 occurred on at least six stem maps. Species specific estimates for both indexes were calculated by

231 considering only reference trees of each species in equation [3].

\section{$232 \quad 3.5$ Accuracy assessment}

The sampling methods were compared using relative bias $(R B)$ and relative root mean square error

234 (RRMSE) (e.g., Temesgen 2003, Temesgen et al. 2011 and Poudel et al. 2015). For each site, sampling 235 method, number of neighbors for the indexes definition and average number of trees in the fixed and 236 variable radius plots, relative bias was computed as:

$$
R B_{j, m, n_{t}, n_{n}}(\%)=100 \frac{\sum_{k=1}^{500}\left[\hat{\bar{Y}}_{k, j, m, n_{t}, n_{n}}-\bar{Y}_{j, n_{n}}\right]}{500 \bar{Y}_{j, n_{n}}}
$$

where $\bar{Y}_{j, n_{n}}$ is the true arithmetic mean index value of the population for site $j$ when neighborhood based indexes are calculated based on $n_{n}$ neighbors. We tested by means of t-tests whether or not for absolute bias), was significantly different than 0 . 


$$
R R M S E_{j, m, n_{t}, n_{n}}(\%)=\frac{100}{\bar{Y}} \sqrt{\frac{\sum_{k=1}^{500}\left[\hat{\bar{Y}}_{k, j, m, n_{t}, n_{n}}-\bar{Y}\right]^{2}}{500}}
$$

242

243

244

245

246

247

248

249

250

251

252

253 254 differences.

\section{Results and discussion}

The $R B$ and the RRMSE for each stem map and species were computed similarly, but only considering those iterations where at least one reference trees of the considered species was selected.

Then the denominator and the summation limits in equations [4] and [5] were changed to $N_{\text {iter,sp }}$. Where $N_{i t e r, s p}$ is the number of iterations for which at least one reference tree belonged to the species of interest. We did not tested for each species whether or not for each combination of: stem maps, method, $n_{n}$ and $n_{t}, R B$ was significantly different than 0 because the species compositions of the stem maps is relatively uneven. This would result in a very different number of observations for each species and therefore different values for the power of the t-test, making interpretations of further comparisons difficult. Finally, factorial analysis of variance (ANOVA) was used to assess if significant differences were present for $R B$ and $R R M S E$ across methods and across methods and species, when changing both $n_{n}$ and $n_{t}$. We accounted for the effect of multiple hypothesis testing by using a Bonferroni correction and when factors were significant we performed a post hoc analysis by computing Tukey's honest significant

The statistical scope of inference of this study is limited to forests adjoining headwater streams within the Density Management Study sites. However, the general principles underlying the sampling methods we examined may be applicable to a wide array of forest types. 

effect on their average values ( $p$-value $=0.99$ for the diameter differentiation index and $p$-value $=0.94$ for species mingling index). This result has important practical consequences for future inventories. By reducing the number of trees the mean value of the studied indexes is not affected, but less neighbors need to be measured for each reference tree. This result partially supports previous research from Sterba (2008) who measured one nearest neighbor for all trees selected with a variable plot sample in the Austrian Alps and concluded that estimates of the diameter differentiation index could be obtained with "only little additional field work". Finally, stand level distribution of NNI indexes are more meaningful than the means studied here. The number of neighbors to use for the index computation was not a significant factor for the average NNI in a stand. Leaving this factor out of the analysis in 269 further studies might be a good compromise solution to approach the more complex problem of estimating stand level distributions of NNI.

For the fixed radius plot method, the t-test for the average of the differences $\hat{\bar{Y}}_{k, j, m, n_{t}, n_{n}}-\bar{Y}$ for the 272 species mingling index were significantly different from 0 in only 3 of the 72 possible combinations of 273 stem map and number of neighbors, $n_{n}$ and $n_{t}$ (Table 2). For the diameter differentiation index, the 274 average difference was, in all cases, not significantly different from 0 . This result supports the idea, that 275 the approximated weights used for this method are not perfect but effective in order to prevent biased 276 estimates of the two considered indexes. For the variable radius plot method the number of 277 combinations of stem maps, $n_{n}$ and $n_{t}$ for which a significant bias was found were 6 and 14 out of 72 278 possible combinations for the species mingling and diameter differentiation index respectively. For the 279 nearest tree and the azimuth method, the number of combinations of stem maps, $n_{n}$ and $n_{t}$ for which a 280 significant bias was found were respectively 16 and 16 for the species mingling, and 8 and 6 for and 
281 diameter differentiation index. Despite trying to correct for bias by incorporating approximated weights, 282 the $V A$ method provided biased results in a number of combinations of $n_{n}$ and $n_{t}$, similar to the NT and $283 A Z$ method (Table 2).

In general, RB was in the range of $[-10 \%, 10 \%]$ for the species mingling index and in the range of [2.5\%,2.5\%] for the diameter differentiation index, however, for certain combinations of stem map, method, $n_{n}$ and $n_{t}$, the absolute value of RB exceeded $10 \%$ and $5 \%$ for each index respectively (Figure 1

287 and Figure 2). The RRMSE was in general below $10 \%$ for the species mingling index and below $4 \%$ for 288 the diameter differentiation index while for certain combinations of stem maps, methods, $n_{n}$ and $n_{t}$, 289 RRMSE exceeded $20 \%$ and $5 \%$ for each index respectively (Figure 1 and Figure 2). The analysis of 290 variance revealed that differences in $R R M S E$ and $R B$ among methods were significant for both 291 variables (Table 3). Pair wise comparisons among methods by means of Tukey's honest significant 292 differences tests showed that FI method had significantly lower RRMSE than any other method, except 293 when compared to the $A Z$ method for species mingling estimation. The between-site variability in $294 R R M S E$ and $R B$ for the remaining methods was high for both indices, making it difficult to draw general 295 conclusions about the performance of the sampling methods (Table 3). Neither $n_{n}$ nor $n_{t}$ had significant 296 effect on $R R M S E$ or $R B$ and interaction terms were not significant either.

298 was significant for the RB and RRMSE of both indexes. The method was again a significant factor for 299 both error measures and indexes, and pairwise comparisons among methods by means of Tukey's 300 honest significant differences tests showed that fixed radius plots had significantly lower RRMSE than 301 any other method (Table 4). 
For the diameter differentiation index the following sequence displays the methods tested in this study sorted by increasing species-specific $R R M S E, F I<(A Z, N T)<V A$. The symbol $<$ indicates that a method on the left is superior in terms of RRMSE (i.e. lower RRMSE) to the method or group of methods (grouped with a parenthesis) on the right. For the species mingling index, the sequence of methods shorted by their species specific RRMSE similar to the previous, however, in this case the RRMSE of the FI method was not significantly smaller than the RRMSE of the $A Z$ method. The variability of $R B$ and $R R M S E$ by methods and species is shown in Figure 3 and Figure 5 respectively for the species mingling index. Variability of $R B$ and $R R M S E$ for the diameter differentiation index estimates is shown in Figure 4 and Figure 6. The FI method was fairly stable in terms of $R R M S E$ and $R B$ among sites for both indexes. The variability of $R R M S E$ and $R B$ for the azimuth and the nearest tree 312 methods was important for certain combinations of species-index. For example, when considering the 313 species mingling index for Douglas fir, variability of $R B$ and $R R M S E$ for the $N T$ method was consistently 314 larger than the variability for the $F I$ and $A Z$ method. Similarly, the variability of $R B$ and $R R M S E$ for 315 diameter differentiation of Western Red Cedar, was larger than that observed for the same species with the FI and NT method. consistently better than the other methods, which suggest that this method should be preferred for

319 further applications when only precision is considered. This method is relatively simple and does not require an important amount of extra field measurements when compared to the nearest tree or

321 azimuth method, and its implementation in the field is straightforward. All methods are designed to 322 select a single reference tree in each sampling point, however, the $A Z$ and $N T$ methods, do not require 323 a first step to determine what trees are included in a plot. Both, the $N T$ and $A Z$ method select trees 324 with probability proportional to the area of an associated polygon, the size and shape of which is 
325 dictated by the sampling system and positions of the trees. The selection bias inherent in the nearest326 tree method has been a topic discussion in natural resources sampling but the azimuth method has 327 been little studied. The simplicity of the $A Z$ and $N T$ selection protocols comes at the expense of 1) a 328 tendency to select more isolated trees and 2) a difficult quantification of inclusion probabilities for each 329 tree. However, for both methods the RRMSE and $R B$, while dependent on the site, were relatively low 330 (Figure 1 and Figure 2). It is therefore reasonable to think that the simplicity of these methods might 331 outweigh their worse performance when compared to the FI method. Unfortunately, precise 332 information about the time and effort required to implement each method in the field was not available 333 for this study. Therefore a proper evaluation of the operational implications of each method was 334 impossible.

In the only other comparison of sampling methods for estimation of NNI published in English, Kint et al. (2004) evaluated two sampling methods, "distance sampling" and "plot sampling". Distance 337 sampling is the random selection of trees from a tree-list, while plot sampling is the selection of a given 338 number of trees that are nearest to a sample point. Distance sampling is a design-unbiased sampling 339 method, while plot sampling is not design-unbiased (for a treatment of the calculation of inclusion areas 340 for this sampling design, see Kleinn and Vilčko (2006). Kint et al. (2004) found that plot sampling had 341 substantially greater bias than distance sampling even with relatively large sample sizes. However, they 342 concluded that plot sampling was a sometimes a better candidate for estimation of diameter 343 differentiation, while distance sampling was always a better candidate for estimation of species 344 mingling.

One assumption of this study has been that a sampler wishes to estimate the arithmetic mean 
347 by stating that "the structural attributes of the reference trees do not represent the relative share of the 348 number of trees but proportions of the forest area". Under this framework, the sampler would actually 349 be interested in estimating the average values that is weighted by the area $a_{i}$ where each tree would be 350 the nearest tree (i.e. the area of the Thiessen polygon of each tree). This weighted average will 351 obviously be different from the arithmetic average $\bar{Y}$ introduced in equation [3] in all but the most 352 uniform of stands. Selection probabilities for the NT method are proportional to $a_{i}$, so the Horvitz353 Thompson estimator can be computed because the terms $a_{i}$ cancel out. In addition, a strong correlation 354 of the selection probabilities (proportional to $a_{i}$ ) with the variable of interest, $a_{i} y_{i}$, are very likely, and 355 would ensure that this method nearly optimal is nearly optimal. Other choices of weights may also be 356 considered. If the index values of large trees are considered to be more meaningful in determining 357 forest structure than those of small trees, weighting by basal area would be appropriate and variable 358 plot sampling would probably be the most efficient system. Regardless of what definition of NNI is 359 adopted by the scientific community, a consistent definition will be helpful in facilitating comparisons 360 between different research studies and moving $\mathrm{NNI}$ from the world of academia to the world of 361 operational forest inventory.

\section{Conclusions}

While NNI have attracted much attention from the forest research community, little work has been done to determine the most efficient (lowest $R R M S E$ ) sampling system for estimating index values. This study was performed to fill that gap by evaluating the performance of four sampling methods for estimating the species mingling and diameter differentiation methods in headwater riparian forests of western Oregon. Of the sampling methods considered, fixed plot sampling consistently had the lowest 
369 other sampling methods was unpredictable and may be substantial under some conditions, however, in 370 most situations was moderately low.

371 The appropriate sampling method to use is dependent on the attribute to be estimated. This study 372 assumed that the sampler is interested in estimating the arithmetic mean index value for a population.

373 Results would differ if a weighted mean was to be estimated.

374 Finally, for further studies aiming at analyzing the performance of different methods for estimation 375 of NNI distributions, keeping the number of neighbors constant seems to be a reasonably good starting 376 point.

377 Acknowledgements to two anonymous reviewers for the helpful and constructive comments provided. 


\section{References}

382

383

384

385

386

387

388

389

390

391

392

393

394

395

396

397

398

399

400

401

402

403

404

405

406

407

408

409

410

411

412

413

Aguirre, O., Hui, G., Gadow, K. von, and Jiménez, J. 2003. An analysis of spatial forest structure using neighbourhood-based variables. For. Ecol. Manag. 183(1-3): 137-145. doi:10.1016/S03781127(03)00102-6.

Dunn, O.J. 1961. Multiple Comparisons Among Means. J. Am. Stat. Assoc. 56(293): 52-64. doi:10.2307/2282330.

Eskelson, B.N.I., Anderson, P.D., Hagar, J.C., and Temesgen, H. 2011. Geostatistical modeling of riparian forest microclimate and its implications for sampling. Can. J. For. Res. 41(5): 974-985. doi:10.1139/x11-015.

Franklin, J.F., and Spies, T.A. 1991. Composition, Function, and Structure of Old-Growth Douglas-Fir Forests. Wildl. Veg. Unmannaged Douglas Fir For.

Füldner, K. 1995. Strukturbeschreibung von Buchen-Edellaubholz-Mischwäldern. (Describing stand structure in mixed beech-deciduous stands). PhD thesis, University Göttingen, Göttingen.

Gadow, K. v, Zhang, C.Y., Wehenkel, C., Pommerening, A., Corral-Rivas, J., Korol, M., Myklush, S., Hui, G.Y., Kiviste, A., and Zhao, X.H. 2012. Forest Structure and Diversity. In Continuous Cover Forestry. Edited by T. Pukkala and K. von Gadow. Springer Netherlands. pp. 29-83. Available from http://link.springer.com/chapter/10.1007/978-94-007-2202-6_2 [accessed 15 July 2016].

Gadow, K. von, and Pogoda, P. 2000. Assessing forest structure and diversity. In Man and Forest. R.K. Kohli, H.P. Singh, S.P. Vij, K.K. Dhir, D.R. Batish and D.K.Khurana. Panjab University Publication., Chandigarh, India. pp. 1-8.

Gadow, K.V. 1993. Zur Bestandesbeschreibung in der Forsteinrichtung. Forst Holz 48(21): 602-606.

García-Abril, A., Núñez, Mv., Grande, Ma., Velarde, Md., Martínez-Obispo, P., and Rodríguez-Solano, R. 2013. Landscape Indicators for Sustainable Forest Management. In Quantitative Techniques in Participatory Forest Management. CRC Press. pp. 263-366. Available from http://dx.doi.org/10.1201/b15366-7 [accessed 10 July 2014].

Haxtema, Z., Temesgen, H., and Marquardt, T. 2012. Evaluation of $n$-Tree Distance Sampling for Inventory of Headwater Riparian Forests of Western Oregon. West. J. Appl. For. 27(3): 109-117. doi:10.5849/wjaf.10-035.

Horvitz, D.G., and Thompson, D.J. 1952. A Generalization of Sampling Without Replacement From a Finite Universe. J. Am. Stat. Assoc. 47(260): 663-685. doi:10.2307/2280784.

Howard, A.F., and Temesgen, H. 1997. Potential financial returns from alternative silvicultural prescriptions in second-growth stands of coastal British Columbia. Can. J. For. Res. 27(9): 14831495. doi:10.1139/x97-114. 
Iles, K. 1979. Systems for the Selection of Truly Random Samples from Tree Populations and Extension of Variable Plot Sampling to the Third Dimension. University of British Columbia. Available from https://books.google.com/books?id=OoaLnQEACAAJ.

Iles, K. 2003. A Sampler of Inventory Topics: A Practical Discussion for Resource Samplers, Concentrating on Forest Inventory Techniques. Kim lles \& Associates, Limited. Available from https://books.google.com/books?id=sGDIAAAACAAJ.

Iles, K. 2009. "Nearest-tree" estimations - A discussion of their geometry. Math. Comput. For. Nat.Resour. Sci. MCFNS Vol 1 No 2 MCFNS August 28 2009. Available from http://mcfns.com/index.php/Journal/article/view/MCFNS.1-47.

Kint, V., Robert, D.W., and Noël, L. 2004. Evaluation of sampling methods for the estimation of structural indices in forest stands. Ecol. Model. 180(4): 461-476. doi:10.1016/j.ecolmodel.2004.04.032.

Kleinn, C., and Vilčko, F. 2006. Design-unbiased estimation for point-to-tree distance sampling. Can. J. For. Res. 36(6): 1407-1414. doi:10.1139/x06-038.

Marquardt, T., Temesgen, H., and Anderson, P.D. 2010. Accuracy and suitability of selected sampling methods within conifer dominated riparian zones. For. Ecol. Manag. 260(3): 313-320. doi:10.1016/j.foreco.2010.04.014.

Marquardt, T., Temesgen, H., Anderson, P.D., and Eskelson, B. 2012. Evaluation of sampling methods to quantify abundance of hardwoods and snags within conifer-dominated riparian zones. Ann. For. Sci. 69(7): 821-828. doi:10.1007/s13595-012-0204-5.

Mason, W.L., Connolly, T., Pommerening, A., and Edwards, C. 2007. Spatial structure of semi-natural and plantation stands of Scots pine (Pinus sylvestris L.) in northern Scotland. Forestry 80(5): 567586. doi:10.1093/forestry/cpm038.

Pommerening, A. 2002. Approaches to quantifying forest structures. Forestry 75(3): 305-324. doi:10.1093/forestry/75.3.305.

Pommerening, A. 2006. Evaluating structural indices by reversing forest structural analysis. Transform. Contin. Cover For. Chang. Environ. Methods Scenar. Anal. 224(3): 266-277. doi:10.1016/j.foreco.2005.12.039.

Pommerening, A., and Stoyan, D. 2006. Edge-correction needs in estimating indices of spatial forest structure. Can. J. For. Res. 36(7): 1723-1739. doi:10.1139/x06-060.

Poudel, K.P., Temesgen, H., and Gray, A.N. 2015. Evaluation of sampling strategies to estimate crown biomass. For. Ecosyst. 2(1): 1-11. doi:10.1186/s40663-014-0025-0.

Pretzsch, H. 1997. Analysis and modeling of spatial stand structures. Methodological considerations based on mixed beech-larch stands in Lower Saxony. For. Ecol. Manag. 97(3): 237-253. doi:10.1016/S0378-1127(97)00069-8. 
470

72

R Core Team. 2016. R: A Language and Environment for Statistical Computing. R Foundation for Statistical Computing, Vienna, Austria. Available from https://www.R-project.org/.

Ripley, B.D. 1977. Modelling Spatial Patterns. J. R. Stat. Soc. Ser. B Methodol. 39(2): 172-212.

Ripley, B.D. 1979. Tests of 'Randomness' for Spatial Point Patterns. J. R. Stat. Soc. Ser. B Methodol. 41(3): 368-374.

Saunders, M.R., and Wagner, R.G. 2008. Long-term spatial and structural dynamics in Acadian mixedwood stands managed under various silvicultural systems. Can. J. For. Res. 38(3): 498-517. doi:10.1139/X07-155.

Schütz, J.P. 1997. Sylviculture 2, la gestion des forêts irrégulières et mélangées. Les Presses polytechniques et universitaires romandes, Lausanne, Switzerland.

Schütz, J.-P., Pukkala, T., Donoso, P.J., and Gadow, K. von. 2012. Historical Emergence and Current Application of CCF. In Continuous Cover Forestry. Edited by T. Pukkala and K. von Gadow. Springer Netherlands. pp. 1-28. Available from http://link.springer.com/chapter/10.1007/97894-007-2202-6_1 [accessed 15 July 2016].

Sterba, H. 2008. Diversity indices based on angle count sampling and their interrelationships when used in forest inventories. Forestry 81(5): 587-597. doi:10.1093/forestry/cpn010.

Temesgen, H. 2003. Evaluation of sampling alternatives to quantify tree leaf area. Canadian Journal of Forest Research 33 (1): 82-95

Temesgen, H., V. Monleon, A Weiskittel, and D. Wilson. 2011. Sampling strategies for efficient estimation of tree foliage biomass. Forest Science 57 (2): 153-163

Whittaker, R.H. 1960. Vegetation of the Siskiyou Mountains, Oregon and California. Ecol. Monogr. 30(3): 279-338. doi:10.2307/1943563.

Zenner, E.K., and Hibbs, D.E. 2000. A new method for modeling the heterogeneity of forest structure. For. Ecol. Manag. 129(1-3): 75-87. doi:10.1016/S0378-1127(99)00140-1. 


\section{Tables}

475 Table1. Summary statistics for each stem map. DF, Douglas-fir; WH, western hemlock; WR, western red 476 cedar; GF, grand fir; PY, Pacific yew; RA, red alder; BM, big-leaf maple; BC, black cottonwood, GC golden 477 chinquapin, PD pacific dogwood, SX Salix sp. N is the total number of trees at each site; $\overline{\boldsymbol{M}}$ and $\overline{\boldsymbol{D}}$ are the 478 average value for the species mingling and diameter differentiation indices respectively.

\begin{tabular}{|c|c|c|c|c|c|c|c|c|c|c|c|c|c|c|c|c|c|c|}
\hline \multirow{3}{*}{ Site } & \multicolumn{6}{|c|}{$n_{n}$} & \multicolumn{11}{|c|}{ Percentage of total density } & \multirow{3}{*}{$\mathbf{N}$} \\
\hline & 2 & & 3 & & 4 & & \multirow[b]{2}{*}{ DF } & \multirow[b]{2}{*}{ WH } & \multirow[b]{2}{*}{ WR } & \multirow[b]{2}{*}{ GF } & \multirow[b]{2}{*}{ PY } & \multirow[b]{2}{*}{ RA } & \multirow[b]{2}{*}{ BM } & \multirow[b]{2}{*}{ BC } & \multirow[b]{2}{*}{ GC } & \multirow[b]{2}{*}{ PD } & \multirow[b]{2}{*}{ SX } & \\
\hline & $\bar{M}$ & $\bar{D}$ & $\bar{M}$ & $\bar{D}$ & $\overline{\bar{M}}$ & $\bar{D}$ & & & & & & & & & & & & \\
\hline BL13 & 0.14 & 0.40 & 0.16 & 0.40 & 0.17 & 0.39 & 85.2 & - & - & - & 0.5 & - & 11.4 & - & - & 2.9 & - & 210 \\
\hline KM17 & 0.43 & 0.27 & 0.43 & 0.27 & 0.45 & 0.27 & 30.1 & 60.3 & 0.8 & - & - & 8.8 & - & - & - & - & - & 239 \\
\hline KM18 & 0.48 & 0.39 & 0.50 & 0.39 & 0.51 & 0.39 & 30.8 & 51.2 & 11.7 & - & - & 6.3 & - & - & - & - & - & 383 \\
\hline KM19 & 0.47 & 0.38 & 0.47 & 0.37 & 0.47 & 0.37 & 49.6 & 30.8 & 17.3 & - & - & 2.1 & - & 0.3 & - & - & - & 341 \\
\hline KM21 & 0.41 & 0.34 & 0.43 & 0.34 & 0.45 & 0.34 & 36.4 & 40.4 & 8.4 & - & - & 14.7 & - & - & - & - & - & 225 \\
\hline OM36 & 0.22 & 0.36 & 0.22 & 0.35 & 0.23 & 0.35 & 73.6 & 26.4 & - & - & - & - & - & - & - & - & - & 239 \\
\hline TH46 & 0.35 & 0.27 & 0.35 & 0.26 & 0.36 & 0.26 & 83.5 & 3.3 & 1.2 & 2.9 & - & 6.6 & 0.4 & 0.4 & 0.8 & 0.4 & 0.4 & 242 \\
\hline TH75 & 0.37 & 0.37 & 0.40 & 0.38 & 0.41 & 0.38 & 65.2 & 4.6 & 3.5 & & - & 2.7 & 23.7 & 0.3 & - & - & - & 371 \\
\hline
\end{tabular}


481 Table 2. T-test $p$-values for each index and combination of stem map, method, number of neighbors and 482 number of trees per plot. Highlighted cells indicate significant differences after performing the 483 Bonferroni correction.

\begin{tabular}{|c|c|c|c|c|c|c|c|c|c|c|c|c|c|c|c|c|c|c|c|}
\hline \multirow{2}{*}{\multicolumn{2}{|c|}{$\begin{array}{c}\text { Index } \\
n_{t}\end{array}$}} & \multicolumn{9}{|c|}{ Species mingling } & \multicolumn{9}{|c|}{ Diameter differentiation } \\
\hline & & 3 & & & 6 & & & 9 & & & 3 & & & 6 & & & 9 & & \\
\hline Site & $n_{n}$ & 2 & 3 & 4 & 2 & 3 & 4 & 2 & 3 & 4 & 2 & 3 & 4 & 2 & 3 & 4 & 2 & 3 & 4 \\
\hline \multirow{4}{*}{ BL13 } & $N T$ & 0.00 & 0.00 & 0.00 & 0.00 & 0.00 & 0.00 & 0.00 & 0.00 & 0.00 & 0.81 & 0.55 & 0.03 & 0.81 & 0.55 & 0.03 & 0.81 & 0.55 & 0.03 \\
\hline & $F I$ & 0.31 & 0.77 & 0.48 & 0.74 & 0.97 & 0.77 & 0.48 & 0.52 & 0.43 & 0.82 & 0.52 & 0.60 & 0.50 & 0.64 & 0.99 & 0.48 & 0.45 & 0.93 \\
\hline & $A Z$ & 0.00 & 0.00 & 0.00 & 0.00 & 0.00 & 0.00 & 0.00 & 0.00 & 0.00 & 0.04 & 0.02 & 0.00 & 0.04 & 0.02 & 0.00 & 0.04 & 0.02 & 0.00 \\
\hline & $V A$ & 0.14 & 0.30 & 0.01 & 0.29 & 0.14 & 0.00 & 0.72 & 0.07 & 0.00 & 0.33 & 0.40 & 0.28 & 0.28 & 0.15 & 0.38 & 0.21 & 0.30 & 0.34 \\
\hline \multirow{4}{*}{ KM17 } & $N T$ & 0.43 & 0.05 & 0.06 & 0.43 & 0.05 & 0.06 & 0.43 & 0.05 & 0.06 & 0.20 & 0.10 & 0.09 & 0.20 & 0.10 & 0.09 & 0.20 & 0.10 & 0.09 \\
\hline & $F I$ & 0.07 & 0.04 & 0.01 & 0.26 & 0.22 & 0.10 & 0.31 & 0.24 & 0.29 & 0.77 & 0.86 & 0.94 & 0.33 & 0.61 & 0.72 & 0.62 & 0.96 & 0.91 \\
\hline & $A Z$ & 0.03 & 0.16 & 0.45 & 0.03 & 0.16 & 0.45 & 0.03 & 0.16 & 0.45 & 0.78 & 0.04 & 0.00 & 0.78 & 0.04 & 0.00 & 0.78 & 0.04 & 0.00 \\
\hline & $V A$ & 0.47 & 0.35 & 0.46 & 0.54 & 0.26 & 0.24 & 0.00 & 0.01 & 0.05 & 0.00 & 0.00 & 0.00 & 0.00 & 0.00 & 0.00 & 0.00 & 0.00 & 0.00 \\
\hline \multirow{4}{*}{ KM18 } & $N T$ & 0.04 & 0.05 & 0.09 & 0.04 & 0.05 & 0.09 & 0.04 & 0.05 & 0.09 & 0.01 & 0.06 & 0.36 & 0.01 & 0.06 & 0.36 & 0.01 & 0.06 & 0.36 \\
\hline & $F I$ & 0.53 & 0.11 & 0.50 & 0.77 & 0.71 & 0.70 & 0.39 & 0.12 & 0.21 & 0.36 & 0.38 & 0.58 & 0.67 & 0.40 & 0.33 & 0.76 & 0.97 & 0.93 \\
\hline & $A Z$ & 0.11 & 0.30 & 0.40 & 0.11 & 0.30 & 0.40 & 0.11 & 0.30 & 0.40 & 0.90 & 0.38 & 0.53 & 0.90 & 0.38 & 0.53 & 0.90 & 0.38 & 0.53 \\
\hline & $V A$ & 0.64 & 0.89 & 0.65 & 0.76 & 0.96 & 0.40 & 0.88 & 0.96 & 0.31 & 0.25 & 0.13 & 0.03 & 0.37 & 0.13 & 0.04 & 0.27 & 0.30 & 0.48 \\
\hline \multirow{4}{*}{ KM19 } & $N T$ & 0.00 & 0.00 & 0.00 & 0.00 & 0.00 & 0.00 & 0.00 & 0.00 & 0.00 & 0.02 & 0.00 & 0.00 & 0.02 & 0.00 & 0.00 & 0.02 & 0.00 & 0.00 \\
\hline & $F I$ & 0.00 & 0.00 & 0.00 & 0.33 & 0.13 & 0.03 & 0.00 & 0.00 & 0.00 & 0.18 & 0.23 & 0.16 & 0.92 & 0.48 & 0.39 & 0.50 & 0.92 & 0.98 \\
\hline & $A Z$ & 0.00 & 0.06 & 0.29 & 0.00 & 0.06 & 0.29 & 0.00 & 0.06 & 0.29 & 0.00 & 0.00 & 0.00 & 0.00 & 0.00 & 0.00 & 0.00 & 0.00 & 0.00 \\
\hline & $V A$ & 0.02 & 0.02 & 0.05 & 0.00 & 0.02 & 0.11 & 0.00 & 0.00 & 0.01 & 0.08 & 0.11 & 0.28 & 0.06 & 0.02 & 0.09 & 0.11 & 0.04 & 0.08 \\
\hline \multirow{4}{*}{ KM21 } & $N T$ & 0.09 & 0.02 & 0.00 & 0.09 & 0.02 & 0.00 & 0.09 & 0.02 & 0.00 & 0.00 & 0.00 & 0.00 & 0.00 & 0.00 & 0.00 & 0.00 & 0.00 & 0.00 \\
\hline & $F I$ & 0.29 & 0.61 & 0.82 & 0.86 & 0.04 & 0.01 & 0.32 & 0.40 & 0.70 & 0.90 & 0.52 & 0.67 & 0.97 & 0.62 & 0.12 & 0.93 & 0.41 & 0.77 \\
\hline & $A Z$ & 0.95 & 0.46 & 0.30 & 0.95 & 0.46 & 0.30 & 0.95 & 0.46 & 0.30 & 0.36 & 0.14 & 0.56 & 0.36 & 0.14 & 0.56 & 0.36 & 0.14 & 0.56 \\
\hline & $V A$ & 0.09 & 0.76 & 0.97 & 0.04 & 0.84 & 0.55 & 0.01 & 0.41 & 0.18 & 0.03 & 0.55 & 0.48 & 0.00 & 0.00 & 0.00 & 0.00 & 0.00 & 0.00 \\
\hline \multirow{4}{*}{ OM36 } & $N T$ & 0.00 & 0.25 & 0.90 & 0.00 & 0.25 & 0.90 & 0.00 & 0.25 & 0.90 & 0.75 & 0.88 & 0.67 & 0.75 & 0.88 & 0.67 & 0.75 & 0.88 & 0.67 \\
\hline & $F I$ & 0.55 & 0.48 & 0.28 & 0.29 & 0.51 & 0.33 & 0.83 & 0.94 & 0.66 & 0.38 & 0.24 & 0.09 & 0.06 & 0.15 & 0.10 & 0.91 & 0.99 & 0.68 \\
\hline & $A Z$ & 0.01 & 0.00 & 0.01 & 0.01 & 0.00 & 0.01 & 0.01 & 0.00 & 0.01 & 0.53 & 0.13 & 0.61 & 0.53 & 0.13 & 0.61 & 0.53 & 0.13 & 0.61 \\
\hline & $V A$ & 0.59 & 0.94 & 0.79 & 0.47 & 0.33 & 0.19 & 0.96 & 0.17 & 0.07 & 0.07 & 0.04 & 0.16 & 0.97 & 0.83 & 0.61 & 0.03 & 0.01 & 0.00 \\
\hline \multirow{4}{*}{ TH46 } & $N T$ & 0.00 & 0.02 & 0.00 & 0.00 & 0.02 & 0.00 & 0.00 & 0.02 & 0.00 & 0.00 & 0.00 & 0.00 & 0.00 & 0.00 & 0.00 & 0.00 & 0.00 & 0.00 \\
\hline & $F I$ & 0.08 & 0.19 & 0.14 & 0.86 & 0.90 & 0.61 & 0.62 & 0.97 & 0.67 & 0.19 & 0.18 & 0.00 & 0.17 & 0.15 & 0.06 & 0.01 & 0.01 & 0.01 \\
\hline & $A Z$ & 0.82 & 0.90 & 0.39 & 0.82 & 0.90 & 0.39 & 0.82 & 0.90 & 0.39 & 0.00 & 0.00 & 0.00 & 0.00 & 0.00 & 0.00 & 0.00 & 0.00 & 0.00 \\
\hline & $V A$ & 0.00 & 0.00 & 0.00 & 0.00 & 0.00 & 0.00 & 0.00 & 0.00 & 0.00 & 0.35 & 0.33 & 0.08 & 0.01 & 0.02 & 0.00 & 0.01 & 0.02 & 0.00 \\
\hline \multirow{4}{*}{ TH75 } & $N T$ & 0.37 & 0.88 & 0.77 & 0.37 & 0.88 & 0.77 & 0.37 & 0.88 & 0.77 & 0.81 & 0.29 & 0.01 & 0.81 & 0.29 & 0.01 & 0.81 & 0.29 & 0.01 \\
\hline & $F I$ & 0.84 & 0.57 & 0.79 & 0.12 & 0.17 & 0.22 & 0.24 & 0.29 & 0.23 & 0.90 & 0.57 & 0.67 & 0.26 & 0.08 & 0.18 & 0.75 & 0.15 & 0.10 \\
\hline & $A Z$ & 0.50 & 0.86 & 0.86 & 0.50 & 0.86 & 0.86 & 0.50 & 0.86 & 0.86 & 0.29 & 0.06 & 0.02 & 0.29 & 0.06 & 0.02 & 0.29 & 0.06 & 0.02 \\
\hline & $V A$ & 0.09 & 0.00 & 0.00 & 0.04 & 0.00 & 0.00 & 0.33 & 0.06 & 0.00 & 0.42 & 0.20 & 0.04 & 0.03 & 0.03 & 0.00 & 0.56 & 0.25 & 0.09 \\
\hline
\end{tabular}


485 Table 3. Analysis of variance for RB and RRMSE for estimation of the overall diameter differentiation and 486 species mingling indexes. The factor method is indicated as $m, n_{n}$ and $n_{t}$ indicate the number of 487 neighbors used to compute the indexes and the average number of trees in the fixed and variable radius 488 plots.

\begin{tabular}{|c|c|c|c|c|c|c|c|c|c|c|}
\hline \multirow[b]{2}{*}{ Factor } & \multicolumn{5}{|c|}{ RB diameter differentiation } & \multicolumn{5}{|c|}{ RRMSE diameter differentiation } \\
\hline & Df & $\begin{array}{l}\text { Sum of } \\
\text { Squares }\end{array}$ & $\begin{array}{l}\text { Mean } \\
\text { square }\end{array}$ & $F$ value & $\operatorname{Pr}(\mathrm{F})$ & Df & $\begin{array}{l}\text { Sum of } \\
\text { Squares }\end{array}$ & $\begin{array}{l}\text { Mean } \\
\text { square }\end{array}$ & F value & $\operatorname{Pr}(\mathrm{F})$ \\
\hline Factor $n_{n}$ & 2 & $3.0 \mathrm{E}-04$ & $1.5 \mathrm{E}-04$ & $1.8 \mathrm{E}-01$ & $8.3 \mathrm{E}-01$ & 2 & $2.0 \mathrm{E}-04$ & $1.0 \mathrm{E}-04$ & $3.2 \mathrm{E}-01$ & $7.3 \mathrm{E}-01$ \\
\hline Factor $n_{t}$ & 2 & $1.6 \mathrm{E}-03$ & $7.9 \mathrm{E}-04$ & $9.6 \mathrm{E}-01$ & $3.8 \mathrm{E}-01$ & 2 & $1.6 \mathrm{E}-04$ & $7.8 \mathrm{E}-05$ & $2.5 \mathrm{E}-01$ & $7.8 \mathrm{E}-01$ \\
\hline Factor method $(m)$ & 3 & $1.6 \mathrm{E}-02$ & $5.4 \mathrm{E}-03$ & $6.6 \mathrm{E}+00$ & $* 2.7 \mathrm{E}-04$ & 3 & $3.1 \mathrm{E}-02$ & $1.0 \mathrm{E}-02$ & $3.2 E+01$ & $*<2 \mathrm{E}-16$ \\
\hline Interaction $n_{n} x * n_{t}$ & 4 & $6.0 \mathrm{E}-05$ & $1.5 \mathrm{E}-05$ & $1.9 \mathrm{E}-02$ & $1.0 \mathrm{E}+00$ & 4 & $1.0 \mathrm{E}-05$ & $2.0 \mathrm{E}-06$ & $8.0 \mathrm{E}-03$ & $1.0 \mathrm{E}+00$ \\
\hline Interaction $n_{n} * m$ & 6 & 4.7E-04 & $7.8 \mathrm{E}-05$ & $9.5 \mathrm{E}-02$ & $1.0 \mathrm{E}+00$ & 6 & $9.4 \mathrm{E}-04$ & $1.6 \mathrm{E}-04$ & $5.0 \mathrm{E}-01$ & $8.1 \mathrm{E}-01$ \\
\hline Interaction $n_{t} * m$ & 6 & $4.6 \mathrm{E}-03$ & 7.7E-04 & $9.4 \mathrm{E}-01$ & 4.7E-01 & 6 & $1.8 \mathrm{E}-04$ & $3.0 \mathrm{E}-05$ & $9.4 \mathrm{E}-02$ & $1.0 \mathrm{E}+00$ \\
\hline Interaction $n_{t} * n_{t} * m$ & 12 & $1.1 \mathrm{E}-04$ & $9.0 \mathrm{E}-06$ & $1.1 \mathrm{E}-02$ & $1.0 \mathrm{E}+00$ & 12 & $2.0 \mathrm{E}-05$ & $2.0 \mathrm{E}-06$ & $6.0 \mathrm{E}-03$ & $1.0 \mathrm{E}+00$ \\
\hline Residuals & 252 & $2.1 \mathrm{E}-01$ & $8.2 \mathrm{E}-04$ & & & 252 & $7.9 \mathrm{E}-02$ & $3.2 \mathrm{E}-04$ & & \\
\hline \multirow[b]{2}{*}{ Factor } & \multicolumn{5}{|c|}{ RB species mingling } & \multicolumn{5}{|c|}{ RRMSE species mingling } \\
\hline & Df & $\begin{array}{l}\text { Sum of } \\
\text { Squares }\end{array}$ & $\begin{array}{c}\text { Mean } \\
\text { square }\end{array}$ & F value & $\operatorname{Pr}(\mathrm{F})$ & Df & $\begin{array}{l}\text { Sum of } \\
\text { Squares }\end{array}$ & $\begin{array}{c}\text { Mean } \\
\text { square }\end{array}$ & F value & $\operatorname{Pr}(\mathrm{F})$ \\
\hline Factor $n_{n}$ & 2 & $9.4 \mathrm{E}-03$ & 4.7E-03 & $4.9 \mathrm{E}-01$ & $6.1 \mathrm{E}-01$ & 2 & $2.0 \mathrm{E}-03$ & $9.9 \mathrm{E}-04$ & $1.6 \mathrm{E}-01$ & $8.6 \mathrm{E}-01$ \\
\hline Factor $n_{t}$ & 2 & $6.0 \mathrm{E}-04$ & $3.0 \mathrm{E}-04$ & $3.2 \mathrm{E}-02$ & $9.7 \mathrm{E}-01$ & 2 & $2.4 \mathrm{E}-03$ & $1.2 \mathrm{E}-03$ & $1.9 \mathrm{E}-01$ & $8.3 \mathrm{E}-01$ \\
\hline Factor method $(m)$ & 3 & $3.1 \mathrm{E}-01$ & $1.0 \mathrm{E}-01$ & $1.1 \mathrm{E}+01$ & *1.1E-06 & 3 & $1.5 \mathrm{E}-01$ & $4.8 \mathrm{E}-02$ & $7.6 \mathrm{E}+00$ & $* 6.9 \mathrm{E}-05$ \\
\hline Interaction $n_{n} x * n_{t}$ & 4 & $4.0 \mathrm{E}-04$ & 1.0E-04 & $1.0 \mathrm{E}-02$ & $1.0 \mathrm{E}+00$ & 4 & $3.0 \mathrm{E}-04$ & $9.0 \mathrm{E}-05$ & $1.3 \mathrm{E}-02$ & $1.0 \mathrm{E}+00$ \\
\hline Interaction $n_{n} * m$ & 6 & $2.1 \mathrm{E}-02$ & $3.5 \mathrm{E}-03$ & 3.7E-01 & $9.0 \mathrm{E}-01$ & 6 & $5.8 \mathrm{E}-03$ & 9.7E-04 & $1.5 \mathrm{E}-01$ & $9.9 \mathrm{E}-01$ \\
\hline Interaction $n_{t} * m$ & 6 & $2.7 \mathrm{E}-03$ & 4.6E-04 & $4.8 \mathrm{E}-02$ & $1.0 \mathrm{E}+00$ & 6 & 2.7E-03 & 4.4E-04 & $7.0 \mathrm{E}-02$ & $1.0 \mathrm{E}+00$ \\
\hline Interaction $n_{t} * n_{t} * m$ & 12 & $5.0 \mathrm{E}-04$ & 4.0E-05 & $4.0 \mathrm{E}-03$ & $1.0 \mathrm{E}+00$ & 12 & $6.0 \mathrm{E}-04$ & $5.0 \mathrm{E}-05$ & 8.0E-03 & $1.0 \mathrm{E}+00$ \\
\hline Residuals & 252 & $2.4 \mathrm{E}+00$ & $9.5 \mathrm{E}-03$ & & & 252 & $1.6 \mathrm{E}+00$ & $6.4 \mathrm{E}-03$ & & \\
\hline
\end{tabular}


490 Table 4. Analysis of variance for RB and RRMSE when estimating diameter differentiation and species

491 mingling indexes by species and method. The factor method is indicated as $m$, the factor species is

492 denoted as $s p, n_{n}$ and $n_{t}$ indicate the number of neighbors used to compute the indexes and the

493 average number of trees in the fixed and variable radius plots. Interactions are denoted as Int.

\begin{tabular}{|c|c|c|c|c|c|c|c|c|c|c|}
\hline \multirow[b]{2}{*}{ Factor } & \multicolumn{5}{|c|}{ RB species mingling } & \multicolumn{5}{|c|}{ RRMSE species mingling } \\
\hline & Df & $\begin{array}{l}\text { Sum of } \\
\text { Squares }\end{array}$ & $\begin{array}{l}\text { Mean } \\
\text { square }\end{array}$ & $F$ value & $\operatorname{Pr}(\mathrm{F})$ & Df & $\begin{array}{l}\text { Sum of } \\
\text { Squares }\end{array}$ & $\begin{array}{l}\text { Mean } \\
\text { square }\end{array}$ & $F$ value & $\operatorname{Pr}(F)$ \\
\hline Factor $n_{n}$ & 2 & $7.0 \mathrm{E}-03$ & $3.6 \mathrm{E}-03$ & $6.2 \mathrm{E}-01$ & $5.4 \mathrm{E}-01$ & 2 & $1.6 \mathrm{E}-02$ & $8.0 \mathrm{E}-03$ & $2.4 \mathrm{E}+00$ & $8.9 \mathrm{E}-02$ \\
\hline Factor $n_{t}$ & 2 & $1.5 \mathrm{E}-02$ & 7.7E-03 & $1.3 \mathrm{E}+00$ & 2.7E-01 & 2 & $7.4 \mathrm{E}-03$ & 3.7E-03 & $1.1 \mathrm{E}+00$ & $3.3 \mathrm{E}-01$ \\
\hline Factor method (m) & 3 & $3.4 \mathrm{E}-02$ & $1.1 \mathrm{E}-02$ & $1.9 \mathrm{E}+00$ & $1.2 \mathrm{E}-01$ & 3 & $6.6 \mathrm{E}-01$ & $2.2 \mathrm{E}-01$ & $6.6 \mathrm{E}+01$ & $* 2.0 \mathrm{E}-16$ \\
\hline Factor species $(s p)$ & 3 & 2.7E-01 & $9.0 \mathrm{E}-02$ & $1.5 \mathrm{E}+01$ & $* 1.2 \mathrm{E}-09$ & 3 & $3.0 \mathrm{E}-01$ & $9.8 \mathrm{E}-02$ & $3.0 \mathrm{E}+01$ & $* 2.0 \mathrm{E}-16$ \\
\hline Int $n_{n} * n_{t}$ & 4 & $0.0 \mathrm{E}+00$ & $1.1 \mathrm{E}-04$ & $1.8 \mathrm{E}-02$ & $1.0 \mathrm{E}+00$ & 4 & $2.0 \mathrm{E}-04$ & $6.0 \mathrm{E}-05$ & $1.9 \mathrm{E}-02$ & $1.0 \mathrm{E}+00$ \\
\hline Int $n_{n} *$ me & 6 & $4.0 \mathrm{E}-03$ & $6.5 \mathrm{E}-04$ & $1.1 \mathrm{E}-01$ & $1.0 \mathrm{E}+00$ & 6 & $3.5 \mathrm{E}-03$ & $5.8 \mathrm{E}-04$ & 1.7E-01 & $9.8 \mathrm{E}-01$ \\
\hline Int $n_{t} * m e$ & 6 & $1.8 \mathrm{E}-02$ & $3.0 \mathrm{E}-03$ & $5.1 \mathrm{E}-01$ & $8.1 \mathrm{E}-01$ & 6 & $1.6 \mathrm{E}-02$ & 2.7E-03 & $8.1 \mathrm{E}-01$ & $5.6 \mathrm{E}-01$ \\
\hline Int $n_{n} *$ species & 6 & $5.0 \mathrm{E}-02$ & $8.3 \mathrm{E}-03$ & $1.4 \mathrm{E}+00$ & $2.1 \mathrm{E}-01$ & 6 & $3.3 \mathrm{E}-02$ & $5.5 \mathrm{E}-03$ & $1.7 E+00$ & $1.3 \mathrm{E}-01$ \\
\hline Int $n_{t} *$ species & 6 & $2.3 \mathrm{E}-02$ & $3.8 \mathrm{E}-03$ & $6.5 \mathrm{E}-01$ & $6.9 \mathrm{E}-01$ & 6 & $1.9 \mathrm{E}-02$ & $3.2 \mathrm{E}-03$ & 9.7E-01 & 4.5E-01 \\
\hline Int $m e *$ species & 9 & $1.5 \mathrm{E}+00$ & $1.6 \mathrm{E}-01$ & $2.7 \mathrm{E}+01$ & $* 2.0 \mathrm{E}-16$ & 9 & 2.0E-01 & $2.2 \mathrm{E}-02$ & $6.7 E+00$ & $* 2.8 \mathrm{E}-09$ \\
\hline Int $n_{n} * n_{t} * m$ & 12 & $1.0 \mathrm{E}-03$ & $8.0 \mathrm{E}-05$ & $1.3 \mathrm{E}-02$ & $1.0 \mathrm{E}+00$ & 12 & $8.0 \mathrm{E}-04$ & 7.0E-05 & $2.1 \mathrm{E}-02$ & $1.0 \mathrm{E}+00$ \\
\hline Int $n_{n} * n_{t} * s p$ & 12 & $1.0 \mathrm{E}-03$ & $1.0 \mathrm{E}-04$ & 1.7E-02 & $1.0 \mathrm{E}+00$ & 12 & 7.0E-04 & $6.0 \mathrm{E}-05$ & 1.7E-02 & $1.0 \mathrm{E}+00$ \\
\hline Int $n_{n} * m e * s p$ & 18 & $6.0 \mathrm{E}-02$ & $3.4 \mathrm{E}-03$ & 5.7E-01 & $9.2 \mathrm{E}-01$ & 18 & $5.2 \mathrm{E}-02$ & $2.9 \mathrm{E}-03$ & $8.8 \mathrm{E}-01$ & $6.0 \mathrm{E}-01$ \\
\hline Int $n_{t} * m e * s p$ & 18 & $1.1 \mathrm{E}-01$ & $6.1 \mathrm{E}-03$ & $1.0 \mathrm{E}+00$ & $4.2 \mathrm{E}-01$ & 18 & $6.5 \mathrm{E}-02$ & 3.6E-03 & $1.1 \mathrm{E}+00$ & $3.5 \mathrm{E}-01$ \\
\hline Int $n_{t} * n_{t} * m e * s p$ & 36 & $3.0 \mathrm{E}-03$ & $9.0 \mathrm{E}-05$ & $1.6 \mathrm{E}-02$ & $1.0 \mathrm{E}+00$ & 36 & 3.7E-03 & $1.0 \mathrm{E}-04$ & $3.1 \mathrm{E}-02$ & $1.0 \mathrm{E}+00$ \\
\hline \multirow[t]{2}{*}{ Residuals } & 822 & $4.8 \mathrm{E}+00$ & $5.9 \mathrm{E}-03$ & & & 822 & $2.7 \mathrm{E}+00$ & $3.3 \mathrm{E}-03$ & & \\
\hline & \multicolumn{5}{|c|}{ RB diameter differentiation } & \multicolumn{5}{|c|}{ RRMSE diameter differentiation } \\
\hline Factor & Df & $\begin{array}{l}\text { Sum of } \\
\text { Squares }\end{array}$ & $\begin{array}{c}\text { Mean } \\
\text { square }\end{array}$ & F value & $\operatorname{Pr}(\mathrm{F})$ & Df & $\begin{array}{l}\text { Sum of } \\
\text { Squares }\end{array}$ & $\begin{array}{c}\text { Mean } \\
\text { square }\end{array}$ & $F$ value & $\operatorname{Pr}(\mathrm{F})$ \\
\hline Factor $n_{n}$ & 2 & $1.7 \mathrm{E}-02$ & 8.7E-03 & 7.4E-01 & $4.8 \mathrm{E}-01$ & 2 & 7.0E-03 & $3.6 \mathrm{E}-03$ & $6.2 \mathrm{E}-01$ & $5.4 \mathrm{E}-01$ \\
\hline Factor $n_{t}$ & 2 & $3.0 \mathrm{E}-03$ & $1.6 \mathrm{E}-03$ & 1.4E-01 & 8.7E-01 & 2 & $1.5 \mathrm{E}-02$ & 7.7E-03 & $1.3 \mathrm{E}+00$ & 2.7E-01 \\
\hline Factor method (m) & 3 & $8.2 \mathrm{E}-01$ & 2.7E-01 & $2.3 E+01$ & *1.9E-14 & 3 & $3.4 \mathrm{E}-02$ & $1.1 \mathrm{E}-02$ & $1.9 \mathrm{E}+00$ & $1.2 \mathrm{E}-01$ \\
\hline Factor species $(s p)$ & 3 & $5.0 \mathrm{E}-01$ & 1.7E-01 & $1.4 \mathrm{E}+01$ & $* 5.6 \mathrm{E}-09$ & 3 & 2.7E-01 & $9.0 \mathrm{E}-02$ & $1.5 \mathrm{E}+01$ & $* 1.2 \mathrm{E}-09$ \\
\hline Int $n_{n} * n_{t}$ & 4 & $0.0 \mathrm{E}+00$ & $1.0 \mathrm{E}-05$ & $1.0 \mathrm{E}-03$ & $1.0 \mathrm{E}+00$ & 4 & $0.0 \mathrm{E}+00$ & $1.1 \mathrm{E}-04$ & $1.8 \mathrm{E}-02$ & $1.0 \mathrm{E}+00$ \\
\hline Int $n_{n} * m$ & 6 & $6.5 \mathrm{E}-02$ & $1.1 \mathrm{E}-02$ & $9.2 \mathrm{E}-01$ & $4.8 \mathrm{E}-01$ & 6 & $4.0 \mathrm{E}-03$ & $6.5 \mathrm{E}-04$ & $1.1 \mathrm{E}-01$ & $1.0 \mathrm{E}+00$ \\
\hline Int $n_{t} * m$ & 6 & $5.0 \mathrm{E}-03$ & 7.5E-04 & $6.4 \mathrm{E}-02$ & $1.0 \mathrm{E}+00$ & 6 & $1.8 \mathrm{E}-02$ & $3.0 \mathrm{E}-03$ & $5.1 \mathrm{E}-01$ & $8.1 \mathrm{E}-01$ \\
\hline Int $n_{n} *$ species & 6 & $4.9 \mathrm{E}-02$ & $8.1 \mathrm{E}-03$ & $6.9 \mathrm{E}-01$ & $6.6 \mathrm{E}-01$ & 6 & $5.0 \mathrm{E}-02$ & $8.3 \mathrm{E}-03$ & $1.4 \mathrm{E}+00$ & $2.1 \mathrm{E}-01$ \\
\hline Int $n_{t} *$ species & 6 & $9.0 \mathrm{E}-03$ & $1.5 \mathrm{E}-03$ & $1.2 \mathrm{E}-01$ & $9.9 \mathrm{E}-01$ & 6 & $2.3 \mathrm{E}-02$ & $3.8 \mathrm{E}-03$ & $6.5 \mathrm{E}-01$ & $6.9 \mathrm{E}-01$ \\
\hline Int $m e *$ species & 9 & $2.2 \mathrm{E}-01$ & $2.4 \mathrm{E}-02$ & $2.1 E+00$ & $3.1 \mathrm{E}-02$ & 9 & $1.5 \mathrm{E}+00$ & $1.6 \mathrm{E}-01$ & $2.7 \mathrm{E}+01$ & $* 2.0 \mathrm{E}-16$ \\
\hline Int $n_{n} * n_{t} * m$ & 12 & $1.0 \mathrm{E}-03$ & $6.0 \mathrm{E}-05$ & $5.0 \mathrm{E}-03$ & $1.0 \mathrm{E}+00$ & 12 & $1.0 \mathrm{E}-03$ & $8.0 \mathrm{E}-05$ & $1.3 \mathrm{E}-02$ & $1.0 \mathrm{E}+00$ \\
\hline $\operatorname{lnt} n_{n} * n_{t} * s p$ & 12 & $2.0 \mathrm{E}-03$ & $2.1 \mathrm{E}-04$ & $1.7 \mathrm{E}-02$ & $1.0 \mathrm{E}+00$ & 12 & $1.0 \mathrm{E}-03$ & $1.0 \mathrm{E}-04$ & 1.7E-02 & $1.0 \mathrm{E}+00$ \\
\hline Int $n_{n} * m * s p$ & 18 & $7.5 \mathrm{E}-02$ & $4.2 \mathrm{E}-03$ & $3.5 \mathrm{E}-01$ & 9.9E-01 & 18 & $6.0 \mathrm{E}-02$ & $3.4 \mathrm{E}-03$ & 5.7E-01 & $9.2 \mathrm{E}-01$ \\
\hline Int $n_{t} * m * s p$ & 18 & $9.1 \mathrm{E}-02$ & $5.0 \mathrm{E}-03$ & $4.3 \mathrm{E}-01$ & $9.8 \mathrm{E}-01$ & 18 & $1.1 \mathrm{E}-01$ & $6.1 \mathrm{E}-03$ & $1.0 \mathrm{E}+00$ & $4.2 \mathrm{E}-01$ \\
\hline $\operatorname{lnt} n_{t} * n_{t} * m * s p$ & 36 & $7.0 \mathrm{E}-03$ & $1.9 \mathrm{E}-04$ & $1.6 \mathrm{E}-02$ & $1.0 \mathrm{E}+00$ & 36 & $3.0 \mathrm{E}-03$ & $9.0 \mathrm{E}-05$ & $1.6 \mathrm{E}-02$ & $1.0 \mathrm{E}+00$ \\
\hline Residuals & 822 & $9.7 \mathrm{E}+00$ & $1.2 \mathrm{E}-02$ & & & 822 & $4.8 \mathrm{E}+00$ & $5.9 \mathrm{E}-03$ & & \\
\hline
\end{tabular}


$494 \quad 8$ Figure captions

495

496

497

498

499

500

501

Figure 1. Relative bias (RB in \%) and RRMSE (\%) for estimation of the overall species mingling index.

502

503

504

505

506

507

508

509 
510

511

512

513

514

515

516 Figure 2. Relative bias (RB in \%) and RRMSE (\%) for estimation of the overall diameter

517 differentiation index.

518

519

520

521

522

523

524

525 
533 mingling index. Species are denoted as: DF, Douglas-fir; WH, western hemlock; WR, western red cedar 534 and RA, red alder.

535

536 
543

544

545

546

547

548

Figure 4. Variability of relative bias (RB) across sites by species and methods for the diameter

549 differentiation index. Species are denoted as: DF, Douglas-fir; WH, western hemlock; WR, western red

550 cedar and RA, red alder.

551

552

553

554

555

556

557

558

559 
561

562

567 methods for the species mingling index. Species are denoted as: DF, Douglas-fir; WH, western hemlock;

568 WR, western red cedar and RA, red alder.

569

570

571

572

573

574

575

576 
583 Figure 6. Variability of relative root mean squared error (RRMSE) across sites by species and

584 methods for the diameter differentiation index. Species are denoted as: DF, Douglas-fir; WH, western 585 hemlock; WR, western red cedar and RA, red alder.

586

587 


\section{Figures}

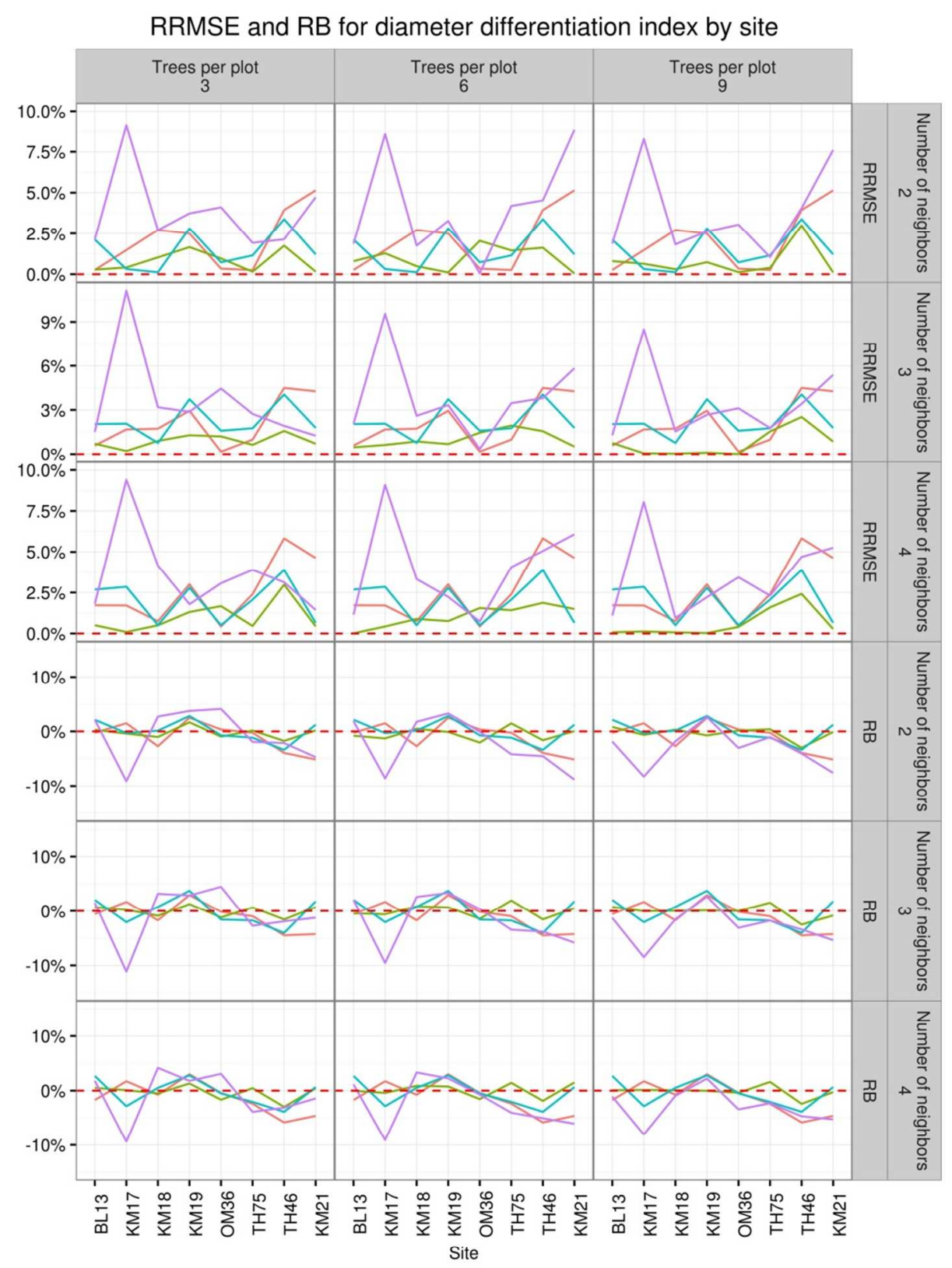

Methods $-\mathrm{NT}-\mathrm{FI}-\mathrm{AZ}-\mathrm{VA}$ 


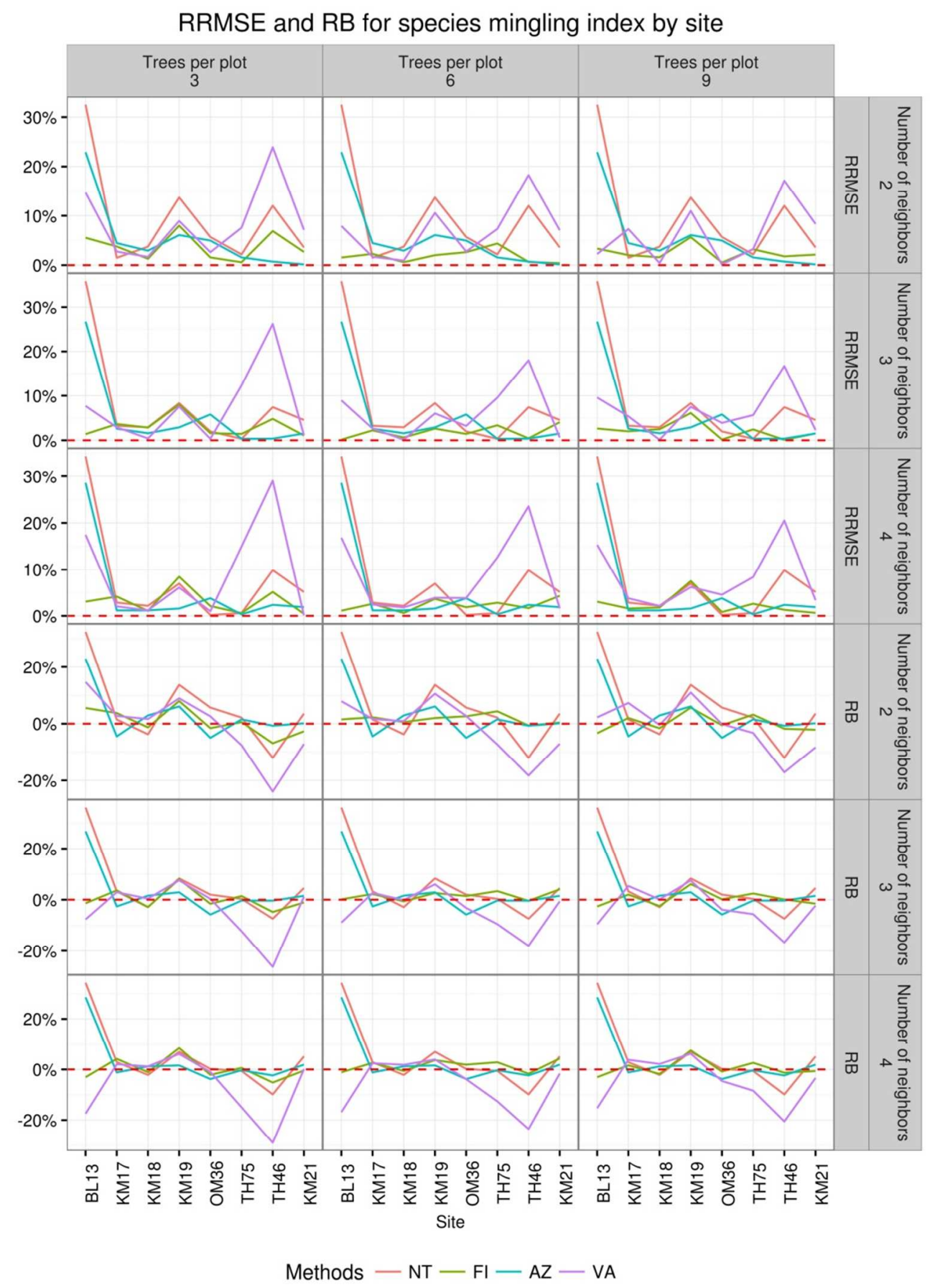




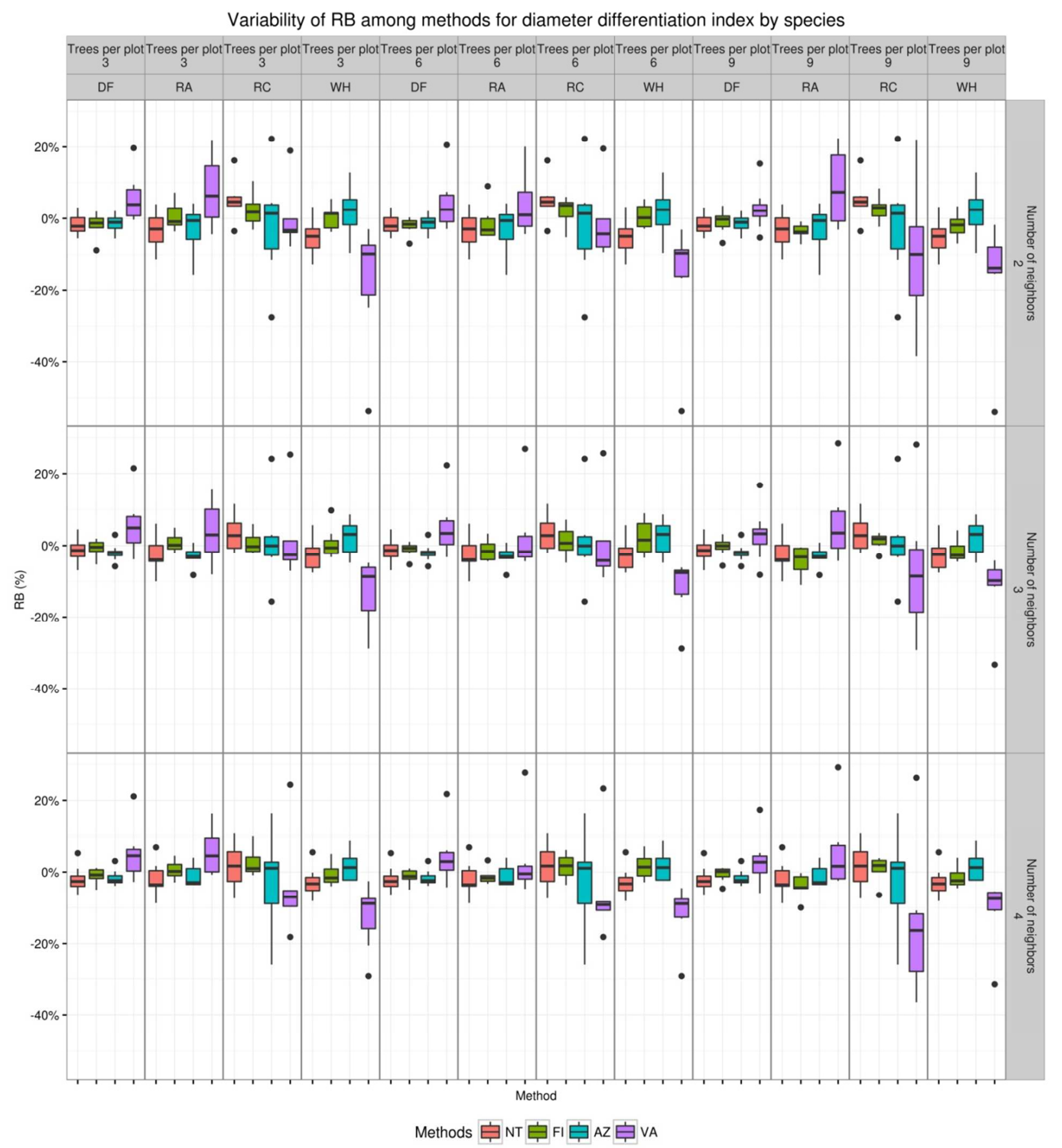




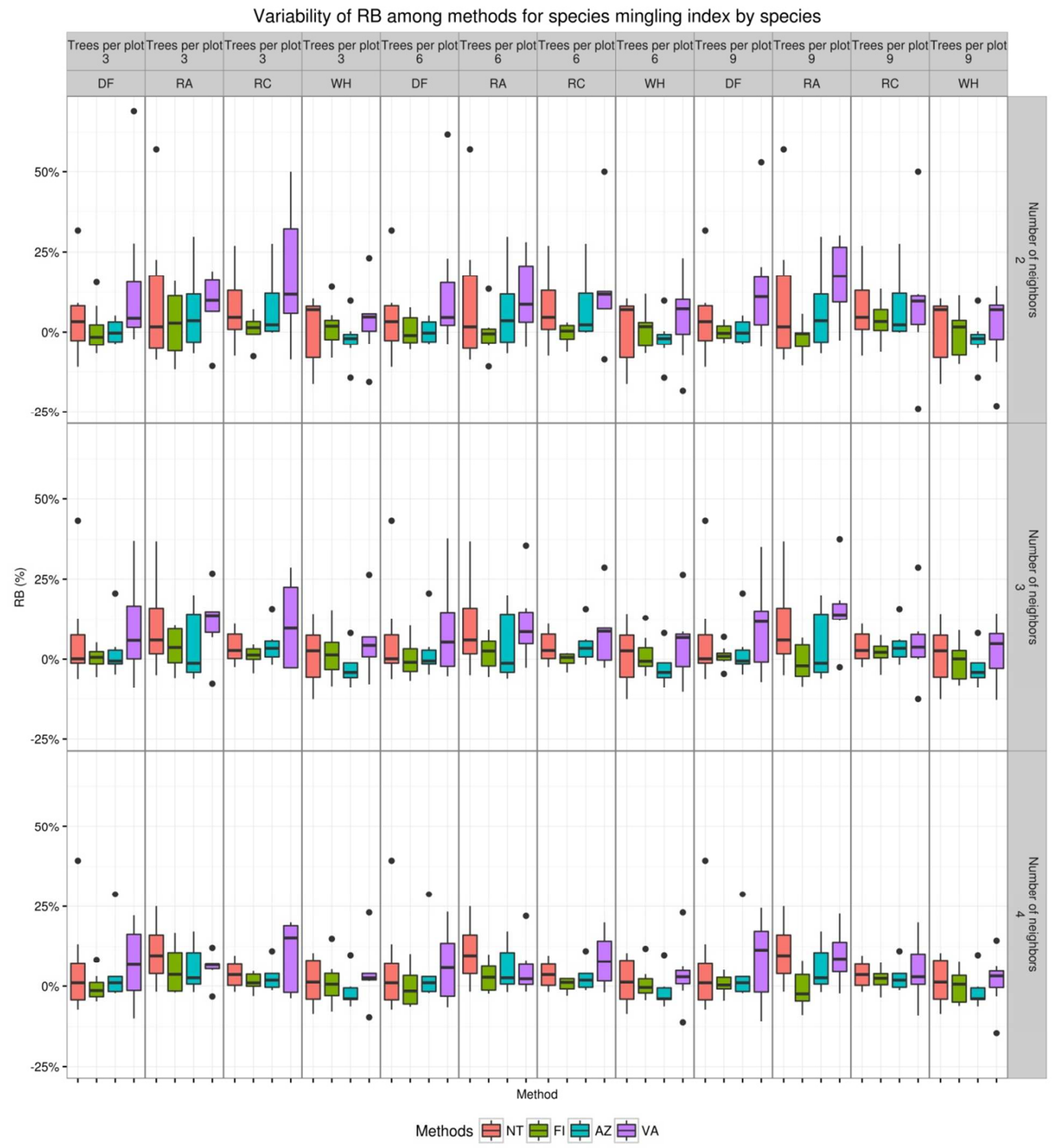




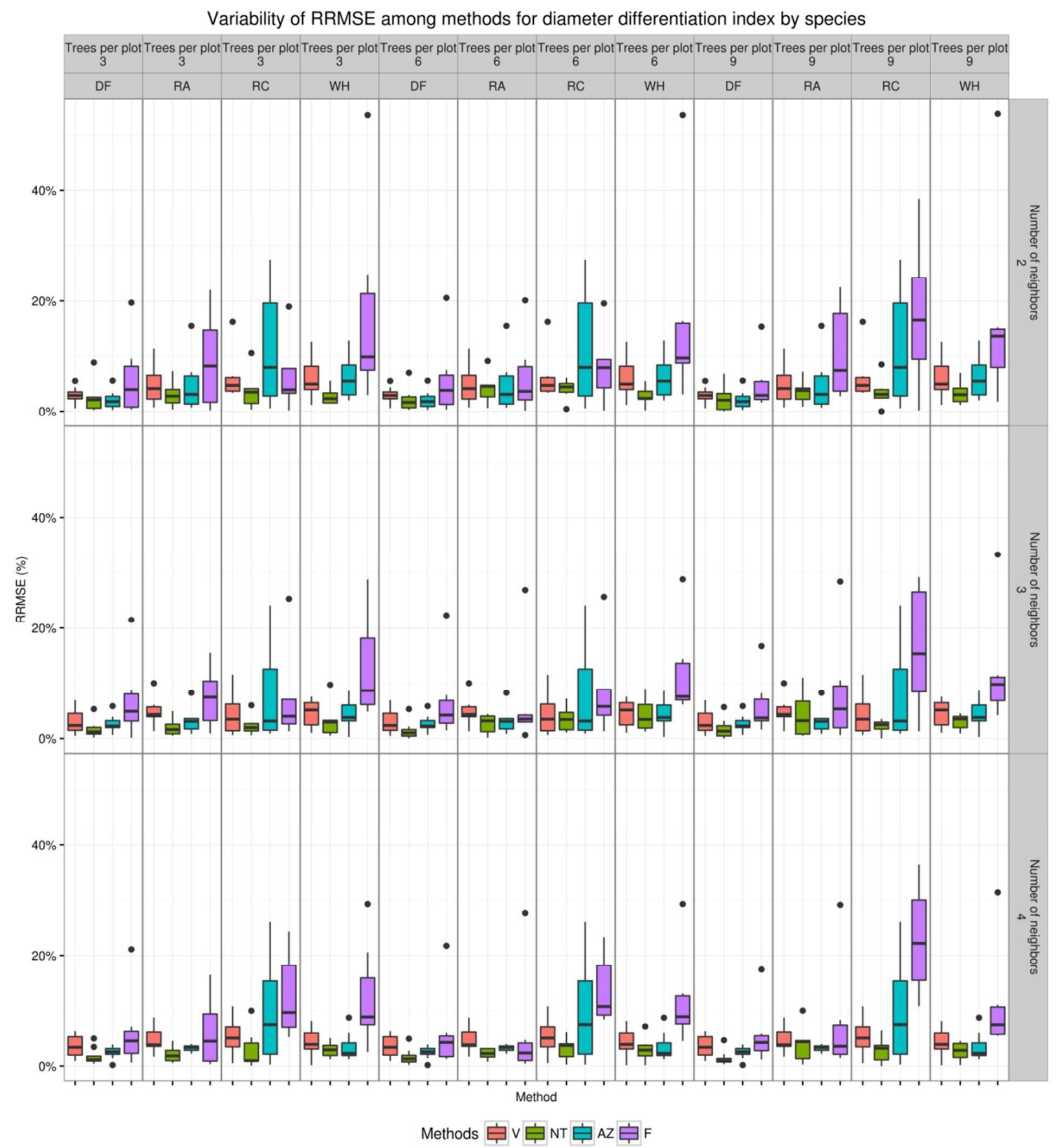

601 
Variability of RRMSE among methods for species mingling index by species

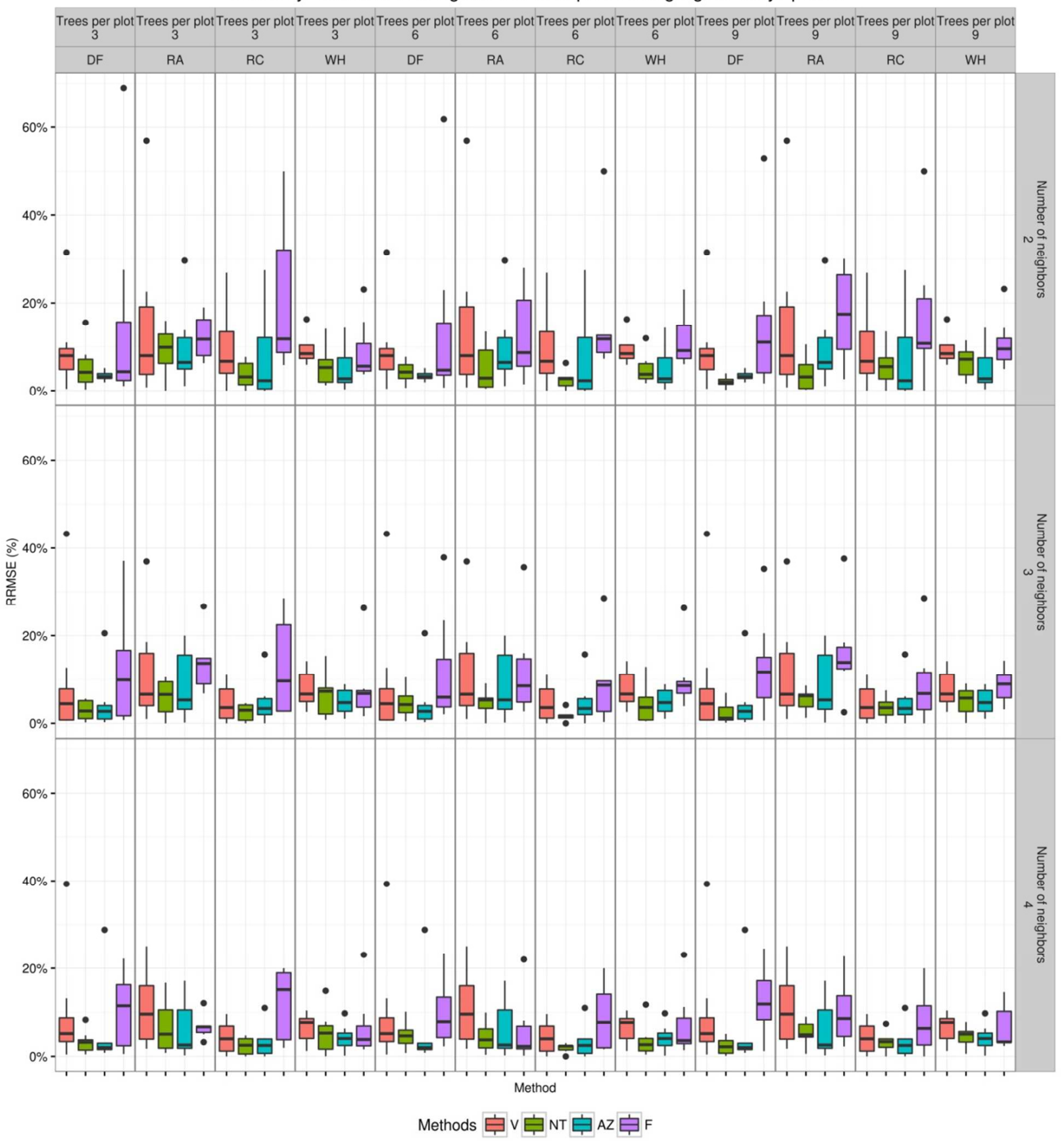

603

604

605 